\title{
Composição Corporal e Puberdade de Leitoas Alimentadas com Níveis Alto e Baixo de Proteína na Dieta
}

\author{
Fábio Enrique Lemos Budiño ${ }^{1}$, Alexandre de Mello Kessler², Mari Lourdes Bernardi ${ }^{3}$
}

\begin{abstract}
RESUMO - Com o objetivo de verificar alterarações na composição corporal, diferentes níveis protéicos (12 e 18\% PB) foram utilizados na dieta de leitoas de reposição, dos 100 aos 221 dias de idade. Durante esse período foram avaliados o peso corporal, espessura de toucinho (ET), manifestação de estro, características do trato reprodutivo e o balanço nitrogenado. Para a determinação do balanço nitrogenado, as leitoas foram submetidas a dois ensaios de digestibilidade (aos 136 e aos 201 dias de idade). Em ambos os ensaios, as leitoas alimentadas com $18 \%$ PB apresentaram maior ingestão, retenção e excreção de nitrogênio e maiores níveis de uréia plasmática e urinária $(\mathrm{P}<0,001)$. A eficiência da utilização de nitrogênio não foi influenciada pelo nível protéico da dieta $(\mathrm{P}>0,05)$. Houve redução de 48\% na excreção de nitrogênio com a dieta menos protéica. Leitoas alimentadas com 12\% PB apresentaram maior ganho de ET (7,4 mm) em comparação às alimentadas com $18 \% \mathrm{~PB}(4,5 \mathrm{~mm})$, dos 100 aos 207 dias de idade $(\mathrm{P}<0,02)$. O peso corporal, peso do útero, comprimento dos cornos uterinos e número de corpos lúteos não foram afetados pelo nível de proteína na dieta. A taxa de detecção de estro, até 25 dias após a exposição das leitoas ao cachaço, foi semelhante para as fêmeas recebendo $12 \%$ (71\%) e 18\% PB (75\%). Os níveis de proteína da dieta afetaram a composição corporal das fêmeas sem que o peso final, o desencadeamento da puberdade e características do trato reprodutivo fossem afetados, indicando que dietas de baixa proteína podem ser utilizadas como estratégia para aumentar a espessura de toucinho de leitoas de reposição.
\end{abstract}

Palavras-chave: excreção de nitrogênio, leitoas, metabolismo, proteína, reprodução

\section{Body Composition and Puberty of Gilts Fed Low and High Protein Diets}

ABSTRACT - With the aim of altering body composition, diets with different protein levels (12 and $18 \mathrm{CP}$ ) were offered to breeding gilts from 100 to 221 days of age. During this period, body weight, backfat thickness, oestrus manifestation, characteristics of reproductive tract and nitrogen balance were evaluated. Nitrogen balance was measured during two metabolism trials (at 136 and at 201 days of age). In both trials, gilts fed $18 \% \mathrm{CP}$ showed higher nitrogen intake, retention and excretion and higher plasmatic and urinary urea levels $(\mathrm{P}<0.001)$. The efficiency of nitrogen utilization was not influenced by dietary protein level $(\mathrm{P}>.05)$. The low-protein diet reduced by $48 \%$ the excretion of nitrogen. Gilts fed $12 \% \mathrm{CP}$ showed a greater backfat change $(7.4 \mathrm{~mm})$ than those fed $18 \% \mathrm{CP}(4.5 \mathrm{~mm})$, between 100 and 207 days of age $(\mathrm{P}<.02)$. Body weight, uterine weight, uterine horns length and number of corpora lutea were not influenced by the level of dietary protein. The rate of oestrus detection, up to 25 days after male exposure, was similar to females receiving $12 \%(71 \%)$ and $18 \% \mathrm{CP}(75 \%)$. The protein level affected body composition without altering body weight, onset of puberty and characteristics of the reproductive tract, suggesting that a low-protein diet can be used as an strategy to increase the backfat thickness of breeding gilts.

Key Words: gilts, metabolism, nitrogen excretion, protein, reproduction

\section{Introdução}

Durante os últimos anos, a espécie suína vem sendo manipulada geneticamente para atender as expectativas de um mercado consumidor que exige carne com menos gordura. No entanto, mesmo um animal com características genéticas para um crescimento muscular mais intenso pode vir a acumular maiores quantidades de tecido adiposo, dependendo da relação energia:proteína de sua dieta.
Dietas com alta proteína (baixa relação energia:proteína) podem limitar o ganho de peso, devido à redução na taxa de deposição de gordura corporal. Por outro lado, dietas com baixa proteína (alta relação energia:proteína) podem limitar o crescimento e desenvolvimento dos tecidos, exceto do tecido adiposo. Conseqüentemente, uma diminuição no teor de proteína na dieta e um enriquecimento em carboidratos ou gordura pode melhorar a eficiência na utilização da EM, resultando em tendência de

\footnotetext{
${ }^{1}$ Aluno de Doutorado da FCAV/UNESP, Jaboticabal-SP. E.mail: fabiobudino@yahoo.com.br

${ }^{2}$ Prof. Adjunto, Dept ${ }^{\circ}$ de Zootecnia, FAGRO/UFRGS, Porto Alegre, RS. E.mail: akessler@vortex.ufrgs.br

3 Prof. Adjunto, Dept ${ }^{\circ}$ de Zootecnia, FAGRO/UFRGS, Porto Alegre, RS. E.mail: bernardi@orion.ufrgs.br
} 
acúmulo de gordura, associada ou não à redução do crescimento muscular (COOKE et al., 1972; NOBLET et al., 1987; KESSLER, 1992).

O processo de seleção para carcaças magras, associado à utilização de dietas com alto teor protéico, tem promovido aumento na taxa de crescimento de tecido magro em detrimento da deposição de gordura na carcaça, nas linhagens modernas. No entanto, a poluição ambiental pela excreção de nitrogênio tem se tornado um problema nos sistemas de produção de suínos. A diminuição desta excreção via redução da ingestão de nitrogênio tem sido estudada na espécie suína, nas fases de crescimento e terminação (KAY e LEE, 1995; LEE et al., 1995; CARTER et al., 1996; MONGÉ et al., 1997).

Leitoas de linhagens modernas, selecionadas para maior deposição muscular e menor teor de gordura, podem apresentar desenvolvimento suficiente para conceber e produzir uma primeira leitegada de tamanho normal, mas podem não possuir proteína corporal e reservas de gordura adequadas para um desempenho reprodutivo satisfatório durante várias parições (GAUGHAN et al., 1995). Devido à excessiva depleção das reservas de gordura durante a primeira lactação (REESE et al., 1984), o desempenho reprodutivo de fêmeas primíparas tem sido insatisfatório, com atraso no retorno ao estro após o desmame e leitegadas menores. Assim, pode-se inferir que reservas adequadas de gordura, por ocasião da cobertura e parto, sejam importantes para o desempenho reprodutivo subseqüente.

A manipulação da composição corporal através da nutrição tem recebido um enfoque importante no que diz respeito à redução do teor de gordura na carcaça de suínos abatidos para o consumo. Vários autores relataram uma maior taxa de deposição de gordura na carcaça de suínos em crescimento e/ou terminação, quando alimentados com baixos teores de proteína (TJONG-A-HUNG et al., 1972; FERREIRA et al., 1983; TYLER et al., 1983; ADEOLA e YOUNG, 1989). Este possível aumento da deposição de gordura tem sido, no entanto, pouco explorado para a alimentação de fêmeas destinadas à reprodução. Considerando que matrizes modernas têm começado sua vida reprodutiva mais cedo e entrado nos rebanhos de cria com menos gordura corporal do que as antigas, é razoável presumir que se as leitoas forem submetidas a um regime alimentar que propicie um aumento da deposição de gordura antes da cobertura, benefícios para o desempenho reprodutivo subseqüente desta fêmea poderão ser obtidos. Assim, a redução da ingestão de proteína por leitoas de reposição poderia resultar em um duplo benefício, pois contemplaria o aumento das reservas de gordura corporal e a diminuição da excreção de nitrogênio para o meio ambiente.

No presente trabalho, foram utilizados dois níveis protéicos (12 e 18\% PB) em dietas para leitoas de reposição, dos 100 aos 221 dias de idade, com o objetivo de verificar alterarações na deposição de gordura corporal e verificar seus efeitos sobre o peso corporal, manifestação de estro, características do trato reprodutivo e balanço nitrogenado.

\section{Material e Métodos}

Foram utilizadas 16 leitoas cruzadas (Landrace $\mathrm{x}$ Large White), com idade média de 100 dias, peso médio inicial de 58,8+4,2 kg eET média de $11+1,0 \mathrm{~mm}$. Entre 100 e 221 dias de idade, as fêmeas foram alimentadas com dietas fareladas isoenergéticas contendo dois níveis de proteína bruta: $12 \%$ (T12\%) e $18 \%$ (T18\%). A composição das dietas, as quais foram formuladas para conter $3275 \mathrm{kcal} \mathrm{EM} / \mathrm{kg}$, é apresentada na Tabela 1.

O trabalho foi subdividido em períodos nos quais os animais permaneceram em baias coletivas e em dois períodos nos quais os animais foram submetidos a ensaios de digestibilidade, com inicio aos 136 e aos 201 dias de idade, respectivamente. As fêmeas foram mantidas em gaiolas metabólicas semelhantes ao modelo descrito por PEKAS (1968), as quais foram adaptadas para possibilitar as coletas de fezes e urina. O funil receptor de urina foi deslocado para a parte posterior, sob o qual foi colocado um balde plástico para receber a urina excretada. Abaixo do piso posterior da gaiola (ripado) e sobre o funil, foi inserido um quadro retangular de madeira revestido de tela plástica, para filtrar a urina e reter as fezes que fossem eventualmente deslocadas do piso ripado. $\mathrm{Na}$ grade posterior foi fixado um anteparo de madeira, possibilitando o escoamento da urina para o funil e impedindo que a mesma fosse perdida.

Durante os períodos em que não estiveram nas gaiolas metabólicas, as fêmeas foram mantidas em baias $(3,00 \times 4,75 \mathrm{~m})$ com piso de cimento, equipadas com bebedouro tipo concha e cochos semi-automáti$\cos$. Água e alimento foram oferecidos à vontade.

Para identificar o inicio e o final do período de coleta de fezes e urina, durante os ensaios de 
digestibilidade, foi utilizado o óxido férrico como marcador fecal, misturado cuidadosamente à ração, na proporção de 1,0\%. Após 7 e 5 dias de adaptação, para o primeiro e segundo ensaio de metabolismo, respectivamente, as fêmeas receberam a ração contendo o marcador. As fezes foram coletadas diariamente, durante um período correspondente a 7

Tabela 1 - Composição das dietas experimentais Table 1 - Composition of experimental diets

\begin{tabular}{|c|c|c|}
\hline $\begin{array}{l}\text { Ingredientes } \% \\
\text { Ingredients }\end{array}$ & $\begin{array}{c}\text { Dieta } 12 \% \mathrm{~PB} \\
12 \% C P \text { diet }\end{array}$ & $\begin{array}{c}\text { Dieta } 18 \% \mathrm{~PB} \\
18 \% C P \text { diet }\end{array}$ \\
\hline Milho & 85,36 & 68,19 \\
\hline Corn & & \\
\hline Farelo de soja & 11,78 & 29,19 \\
\hline $\begin{array}{l}\text { Soybean meal } \\
\text { Fosfato bicálcico } \\
\text { Dicalcium phosphate }\end{array}$ & 1,06 & 0,96 \\
\hline $\begin{array}{l}\text { Calcário calcítico } \\
\text { Limestone }\end{array}$ & 0,97 & 0,97 \\
\hline $\begin{array}{l}\text { Sal } \\
\text { Salt }\end{array}$ & 0,45 & 0,45 \\
\hline $\begin{array}{l}\text { DL-metionina } \\
\text { DL-methionine }\end{array}$ & - & 0,09 \\
\hline $\begin{array}{l}\mathrm{L}-\text { lisina } \\
L \text { - lysine }\end{array}$ & 0,15 & 0,01 \\
\hline $\begin{array}{l}\mathrm{L} \text { - treonina } \\
L \text { - threonine }\end{array}$ & 0,01 & - \\
\hline $\begin{array}{l}\text { Colina } \\
\text { Choline }\end{array}$ & 0,08 & - \\
\hline $\begin{array}{l}\text { Premix vitamínico } \\
\text { Vitamin mix }\end{array}$ & 0,03 & 0,03 \\
\hline $\begin{array}{l}\text { Premix mineral } \\
\text { Mineral mix }\end{array}$ & 0,10 & 0,10 \\
\hline $\begin{array}{l}\text { Antimicrobiano } \\
\text { Antibiotic } \\
\text { Composição calculada } \\
\text { Calculated composition }\end{array}$ & 0,01 & 0,01 \\
\hline $\begin{array}{l}\text { Matéria Seca, \% } \\
\text { Dry matter }\end{array}$ & 88,41 & 88,55 \\
\hline $\begin{array}{l}\text { Proteína Bruta, \% } \\
\text { Crude protein }\end{array}$ & 12,00 & 18,00 \\
\hline $\begin{array}{l}\text { Energia metabolizável, } \\
\mathrm{kcal} / \mathrm{kg} \\
\text { Metabolizable energy }\end{array}$ & 3275 & 3275 \\
\hline $\mathrm{Ca} \%$ & 0,75 & 0,75 \\
\hline $\begin{array}{l}\text { Fósforo disponível, \% } \\
\text { Available phosphorus }\end{array}$ & 0,30 & 0,30 \\
\hline $\begin{array}{l}\text { Lisina, } \% \\
\text { Lysine }\end{array}$ & 0,66 & 1,00 \\
\hline Metionina + Cistina, $\%$ & 0,44 & 0,65 \\
\hline $\begin{array}{l}\text { Treonina, } \% \\
\text { Threonine }\end{array}$ & 0,46 & 0,70 \\
\hline
\end{tabular}

${ }^{1}$ Quantidade por kg (amount per kg): vit. A, $5.000 \mathrm{UI}$; vit. $\mathrm{D}_{3}, 1.000 \mathrm{UI}$; vit.E, $10 \mathrm{mg}$; vit. $K_{3} 1 \mathrm{mg}$; vit. $B_{2}, 3 \mathrm{mg}$; vit. $B_{12}, 0,015 \mathrm{mg}$; niacina (niacin), $15 \mathrm{mg}$; biotina (biotin), 0,05 mg; ácido pantotênico (pantothenic acid), $8 \mathrm{mg}$.

${ }^{2}$ Quantidade (amount), mg/kg: Fe, 60; Zn, 100; Mn, 40; Cu, 10; I, 0,15; Se, 0,2 . dias de consumo. Após a coleta, as fezes foram pesadas e uma alíquota correspondendo a $10 \%$ foi armazenada e congelada, em sacos plásticos.

Vinte e quatro horas após ter sido oferecida a ração com marcador, a urina foi coletada em baldes plásticos contendo $20 \mathrm{~mL}$ de uma solução de ácido sulfúrico a $50 \%$. A urina coletada foi pesada e uma alíquota representando $10 \%$ do total coletado foi armazenada, sob forma congelada, em recipientes plásticos.

Coletas de sangue efetuadas através de punção da veia cava anterior foram efetuadas aos 151 e aos 215 dias para a determinação dos níveis plasmáticos de uréia. As amostras de sangue (7-10 mL/animal) foram centrifugadas ( $3000 \mathrm{rpm} / 15 \mathrm{~min})$, o plasma foi recuperado e armazenado a $-20^{\circ} \mathrm{C}$ para posterior análise.

A concentração de uréia nas amostras de plasma e, também, nas amostras de urina (diluídas 50x) coletadas durante o período de execução dos ensaios de digestibilidade, foi determinada através de ensaio enzimático.

A matéria seca das rações e das fezes (previamente secas em estufa a $60^{\circ} \mathrm{C}$ ), bem como o teor de nitrogênio e proteína bruta foram determinados conforme as normas da ASSOCIATION OF OFICIAL ANALITICAL CHEMISTS - AOAC (1975). Todas as determinações foram feitas em duplicata. O teor de nitrogênio das amostras de urina foi determinado por intermédio do sistema MicroKjeldahl, adaptado do método da AOAC (1975).

A energia bruta da ração e fezes foi determinada pela queima pressurizada com oxigênio em bomba calorimétrica. A energia bruta da urina foi calculada conforme a equação de JUST (1982). A energia líquida foi estimada a partir das medidas individuais de EM, ajustadas conforme a composição da dieta, de acordo com a equação descrita por NOBLET et al. (1994).

$\mathrm{O}$ peso das leitoas foi medido em várias idades (117, 136, 153, 177, 201 e 216 dias de idade). A espessura de toucinho foi medida nas seguintes idades: 138, 151, 162, 172, 193, 207 e ao abate (221 dias). Nas seis primeiras avaliações a medida foi efetuada na altura da última costela $(\mathrm{P} 2)$, a $6 \mathrm{~cm}$ da linha média, com aparelho de ultra-som. Aos 221 dias de idade, a medida foi efetuada com paquímetro, após o abate dos animais. As medidas foram efetuadas na altura da primeira costela, da última costela e da última vértebra lombar, correspondendo respectivamente aos pontos $\mathrm{P} 1, \mathrm{P} 2$ e P3, segundo o Método Brasileiro de Classificação de Carcaças da ABCS (1973). Em 
cada um desses três pontos foram efetuadas duas medidas, uma considerando 2 e a outra 3 camadas de gordura.

Entre as duas baias coletivas onde estavam alojadas as fêmeas havia uma baia medindo 3,00 x 1,50 $\mathrm{m}$, na qual foi alojado um cachaço de 2 anos de idade para estimular as fêmeas a entrar em estro. A exposição das fêmeas ao macho iniciou quando as mesmas estavam com uma idade média de 163 dias. $\mathrm{O}$ cachaço permaneceu na baia individual que se localizava entre as baias das leitoas, podendo estimular igualmente os dois lotes de leitoas. O estro começou a ser verificado após a introdução do macho, durante 38 dias, através de duas observações por dia (8:00 h e 18:00 h), sendo considerada em estro a fêmea que reagisse positivamente ao reflexo de imobilização, após a realização de pressão no dorso da mesma, na presença do cachaço.

Logo após o abate (221 dias de idade), foram coletados os tratos reprodutivos das leitoas, nos quais foram realizadas as seguintes avaliações: comprimento dos cornos uterinos; peso do útero; número de corpos lúteos e presença ou ausência de corpos albicans nos ovários.

O delineamento experimental utilizado foi completamente casualizado. O comprimento dos cornos uterinos, o peso do útero, o número de corpos lúteos e os dados correspondentes aos dois ensaios de metabolismo foramanalisados estatisticamente pelo procedimento GLM do SAS (1989). Os dados referentes aos ensaios de digestibilidade foram analisados em conjunto, tendo sido considerados os efeitos do nível de proteína, do período de realização dos ensaios e a interação entre estes dois fatores. O peso e a espessura de toucinho foram submetidos à análise univariada de medidas repetidas pelo procedimento PROC MIXED (LATOUR et al., 1994). Diferenças no percentual de fêmeas em estro foram avaliadas pelo teste qui-quadrado.

\section{Resultados e Discussão}

Não houve interação entre o nível protéico da dieta e o período em que foram realizados os ensaios de digestibilidade, para nenhum dos itens avaliados $(\mathrm{P}>0,05)$. Não houve efeito $(\mathrm{P}>0,05)$ do nível protéico da dieta sobre a digestibilidade da matéria seca, a digestibilidade e metabolizabilidade da energia, mas foi constatado aumento na digestibilidade da proteína $(\mathrm{P}<0,01)$ para as fêmeas alimentadas com a dieta contendo $18 \%$ PB (Tabela 2).
Vários autores (HOLMES et al., 1980; JUST, 1982; NOBLET et al., 1987; PIMENTA et al., 1998) reportaram acréscimo da digestibilidade da proteína, à medida que o teor desta aumenta na dieta. A alteração na proporção dos ingredientes utilizados, para atingir níveis diferentes de $\mathrm{PB}$, pode exercer influência sobre este parâmetro, já que o farelo de soja normalmente tem PB mais digestível que os grãos de cereais (JUST, 1982). Além disto, considerando que existe uma taxa fixa de perda fecal endógena de $\mathrm{N}$, seja por unidade de peso metabólico ou por unidade de matéria seca consumida, esta parcela representa maior proporção de $\mathrm{N}$ fecal total nas dietas com baixa $\mathrm{PB}$, em que a quantidade de $\mathrm{N}$ não digerido é menor (SCHNEIDER e FLATT, 1975; KESSLER, 1992). Dessa forma, as leitoas que consumiram a dieta mais protéica $(18 \% \mathrm{~PB})$ apresentaram um $\mathrm{N}$ fecal total proporcionalmente menor, resultando em maior digestibilidade da proteína.

As leitoas que consumiram a dieta com $18 \%$ PB retiveram mais nitrogênio, porém apresentaram maior excreção, sobretudo de $\mathrm{N}$ urinário, em comparação às fêmeas que receberam 12\% PB (Tabela 2), confirmando observações anteriores do aumento na excreção de $\mathrm{N}$, à medida que se elevou o teor de proteína na dieta (GATEL, 1994; LEE et al., 1995; MONGÉ et al., 1997). GATEL (1994) observou que ao reduzir a ingestão de nitrogênio em 7,8\%, houve redução de $19 \%$ na excreção de nitrogênio, para suínos em terminação. No presente estudo, a dieta com $12 \%$ PB levou a uma ingestão de nitrogênio em média $45 \%$ inferior à da dieta $18 \% \mathrm{~PB}$, tendo ocorrido redução média de $48 \%$ na excreção de nitrogênio. Isto representa diminuição de $8,0 \%$ na excreção de $\mathrm{N}$, a cada redução de uma unidade percentual no teor de proteína da dieta, semelhante à redução próxima de $8,5 \%$ observada por outros autores (CARTER et al., 1996; MONGÉ et al., 1997).

A eficiência da utilização do nitrogênio (nitrogênio retido/ingerido) não foi influenciada pelo nível protéico da dieta $(\mathrm{P}>0,05)$, mas houve diminuição da eficiência no segundo ensaio em relação ao primeiro $(\mathrm{P}<0,02)$. A redução de $27 \%$, em média, na eficiência de utilização do $\mathrm{N}$ do ensaio 1 para o ensaio 2, confirma as observações de CARR et al. (1977) de que as necessidades de proteína e aminoácidos tendem a diminuir em relação ao peso metabólico, à medida que o suíno cresce. MONGÉ et al. (1997) observaram que índices de $60-70 \%$ de eficiência de utilização do $\mathrm{N}$, para suínos entre 24-61 kg, diminuíram para valo- 
Tabela 2 - Balanço nitrogenado de leitoas alimentadas com dietas contendo diferentes níveis de proteína durante o primeiro (136 a 153 dias) e o segundo (201 a 216 dias de idade) ensaio de digestibilidade

Table 2 - Nitrogen balance of gilts fed diets with different protein levels during the first (136 to 153 days) and the second (201 to 216 days of age) metabolism trial

\begin{tabular}{|c|c|c|c|c|c|c|}
\hline \multirow[b]{2}{*}{ Itens } & \multicolumn{2}{|c|}{$\begin{array}{l}\text { Primeiro ensaio } \\
\quad \text { First trial }\end{array}$} & \multicolumn{2}{|c|}{$\begin{array}{l}\text { Segundo ensaio } \\
\text { Second trial }\end{array}$} & \multicolumn{2}{|c|}{$\begin{array}{l}\text { Nível de significância } \\
\text { Level of significance }\end{array}$} \\
\hline & $12 \%$ & $18 \%$ & $12 \%$ & $18 \%$ & $\begin{array}{l}\text { Proteína } \\
\text { Protein } \\
\end{array}$ & $\begin{array}{c}\text { Ensaio } \\
\text { Trial } \\
\end{array}$ \\
\hline $\begin{array}{l}\text { Consumo de MS, g } \\
\text { DM intake }\end{array}$ & 1882,7 & 2052,7 & 2417,9 & 3026,1 & 0,002 & 0,0001 \\
\hline $\begin{array}{l}\text { CDMS, } \% \\
C D D M\end{array}$ & 87,4 & 87,5 & 88,6 & 87,9 & 0,711 & 0,343 \\
\hline $\begin{array}{l}\mathrm{CDEB}, \% \\
C D G E\end{array}$ & 86,7 & 87,7 & 88,5 & 88,2 & 0,676 & 0,183 \\
\hline $\begin{array}{l}\text { CMEB, } \% \\
C M G E\end{array}$ & 84,4 & 84,2 & 85,6 & 84,4 & 0,372 & 0,393 \\
\hline $\begin{array}{l}\mathrm{CDPB}, \% \\
C D C P\end{array}$ & 83,9 & 87,8 & 85,8 & 87,9 & 0,008 & 0,378 \\
\hline $\begin{array}{l}\text { Nitrogênio ingerido } \\
\text { Nitrogen intake }\end{array}$ & 1,12 & 2,07 & 1,01 & 1,86 & 0,0001 & 0,132 \\
\hline $\begin{array}{l}\text { Nitrogênio retido }{ }^{1} \\
\text { Nitrogen retained }\end{array}$ & 0,425 & 0,699 & 0,271 & 0,447 & 0,0009 & 0,002 \\
\hline $\begin{array}{l}\text { Nitrogênio fecal } \\
\text { Fecal nitrogen }\end{array}$ & 0,183 & 0,252 & 0,148 & 0,221 & 0,002 & 0,108 \\
\hline $\begin{array}{l}\text { Nitrogênio urinário } \\
\text { Urinary nitrogen }\end{array}$ & 0,512 & 1,119 & 0,591 & 1,192 & 0,0001 & 0,284 \\
\hline $\begin{array}{l}\text { Nitrogênio excretado }{ }^{1} \\
\text { Nitrogen excreted }\end{array}$ & 0,695 & 1,371 & 0,739 & 1,413 & 0,0001 & 0,596 \\
\hline ERN, \% & 36,9 & 33,6 & 27,8 & 23,7 & 0,331 & 0,0186 \\
\hline
\end{tabular}

ERN $=$ Eficiência da retenção de nitrogênio (Efficiency of nitrogen retention).

Valores expressos em g/dia/kg PV0,75 (Values expressed as g/day/kg BW0.75).

res próximos a 40\% para suínos entre $100-115 \mathrm{~kg}$.

Os valores médios de retenção diária de $\mathrm{N}$, conforme estimado pelas equações do NRC (1998), para suínos de genótipo moderno e com pesos médios correspondentes ao peso das fêmeas, durante os ensaios 1 e 2 são, respectivamente, de 20 e 15,5 g/dia. Para o ensaio 1, estes valores calculados estão mais próximos dos observados para o nível protéico de $18 \%$ (13 e $21 \mathrm{~g} /$ dia para $\mathrm{T} 12$ e $\mathrm{T} 18 \%$ ), enquanto no ensaio 2, os valores calculados são intermediários aos observados (12 e 19 g/dia para T12 e T18\%). A restrição imposta pela dieta com menor teor protéico foi, provavelmente, compensada pelo acúmulo de reservas corporais de gordura, o que é desejável em leitoas pré-púberes. A utilização de dietas com este teor protéico representaria uma redução aproximada de $20 \mathrm{~kg}$ na proteína consumida e de $2 \mathrm{~kg}$ de $\mathrm{N}$ excretado por fêmea, dos 100 até 220 dias de idade.

Apesar de haver diferença no nitrogênio excretado, entre os tratamentos, isto não influenciou na metabolizabilidade da energia bruta. NOBLET et al. (1987) postularam que o catabolismo da proteína digerida em excesso, para fins energéticos, resulta em aumento da perda de energia na urina. Outros autores (HOLMES et al., 1980) explicaram que isto ocorre por causa do aumento da excreção nitrogenada via urina, ocorrendo um gasto metabólico composto pelas perdas energéticas na degradação de aminoácidos, síntese de uréia e sua excreção pela urina. Desta forma, é esperada uma redução da eficiência energética em função de maiores níveis de PB da dieta, pelo aumento da relação proteína/gordura depositadas e, principalmente, por causa da menor eficiência de uso da EM consumida, representada pela proteína dietética que é catabolisada e não retida no organismo animal. Como esta quantidade aumenta linearmente com o aumento na PB da dieta, é possível que dietas calculadas para conter a mesma EM tenham de fato menor conteúdo de energia útil, à medida que aumenta o nível de $\mathrm{PB}$. A redução na energia líquida em dietas hiperprotéicas já foi demonstrada anteriormente (JUST, 1982; NOBLET et al., 1994) e ocorre, também, porque as rotas de geração de ATP e/ou síntese de gordura corporal, a 
partir de aminoácidos desaminados, são menos eficientes do que aquelas a partir de carboidratos e gordura. Ajustando os valores medidos de EM, no presente experimento, pelas equações de NOBLET et al. (1994), foi constatada EL superior $(\mathrm{P}<0,003)$ para a dieta menos protéica $(2927$ e $2816 \mathrm{kcal} / \mathrm{kg} \mathrm{MS}$, para 12 e $18 \%$ PB, respectivamente). Além disto, como a retenção de $\mathrm{N}$ foi menor com a dieta de baixa proteína, infere-se que uma parcela maior da energia consumida ficaria disponível para a lipogênese, nas fêmeas consumindo esta dieta.

Os níveis plasmáticos e urinários de uréia foram significativamente maiores $(\mathrm{P}<0,001)$ para as fêmeas recebendo a dieta com 18\% PB (Tabela 3). A uréia plasmática aumentou do primeiro para o segundo ensaio, nas fêmeas alimentadas com $12 \% \mathrm{~PB}(\mathrm{P}<0,05)$, enquanto os teores de uréia urinária aumentaram significativamente do primeiro para o segundo ensaio, em ambos os grupos de fêmeas $(\mathrm{P}<0,05)$.

BROWN e CLINE (1974) observaram decréscimo na excreção urinária de uréia, quando a proteína da dieta de suínos diminuiu de 16 para 7,4\%. Maior excreção urinária de uréia, devido ao excesso de proteína bruta, foi também observada por outros autores (FOX et al., 1988; KINYAMU e EWAN, 1994). O aumento dos teores de uréia sangüínea observado para as fêmeas do T18\% sugere que houve excesso de proteína na ração e sobra de aminoácidos, levando provavelmente a aumento da eliminação de uréia, o que foi confirmado pelos maiores níveis de uréia urinária nas leitoas recebendo $18 \%$ PB. Isto sugere que a medida da concentração plasmática de uréia pode ser um método auxiliar na determinação das exigências protéicas de suínos, conforme argumentado por CHEN et al. (1995).

Nas diversas pesagens efetuadas ao longo do trabalho, não foi constatado efeito do nível protéico da dieta sobre o peso das leitoas ( $\mathrm{P}>0,05$; Tabela 4) confirmando as observações de PINHEIRO MACHADO (1992), o qual avaliou o efeito de diferentes níveis de proteína (11,5 e 19\%), em fêmeas suínas, na fase de terminação. Da mesma forma, O'DOWD et

Tabela 3 - Uréia plasmática e urinária de leitoas alimentadas com dois níveis de proteína, durante o primeiro (136 a 153 dias de idade) e segundo (201 a 216 dias de idade) ensaios de digestibilidade

Table 3 - Plasmatic and urinary urea levels of gilts fed two protein levels during the first (136 to 153 days of age) and the second (201 to 216 days of age) metabolism trials

\begin{tabular}{|c|c|c|c|c|c|c|c|}
\hline \multirow[b]{2}{*}{ Itens } & \multicolumn{2}{|c|}{$\begin{array}{l}\text { Primeiro ensaio } \\
\text { First trial }\end{array}$} & \multicolumn{2}{|c|}{$\begin{array}{l}\text { Segundo ensaio } \\
\text { Second trial }\end{array}$} & \multicolumn{3}{|c|}{$\begin{array}{l}\text { Nível de significância } \\
\text { Level of significance }\end{array}$} \\
\hline & $12 \%$ & $18 \%$ & $12 \%$ & $18 \%$ & $\begin{array}{l}\text { Proteína } \\
\text { Protein }\end{array}$ & $\begin{array}{l}\text { Ensaio } \\
\text { Trial }\end{array}$ & $\begin{array}{l}\text { Interação } \\
\text { Interaction }\end{array}$ \\
\hline $\begin{array}{l}\text { Uréia plasmática } \\
\text { Plasmatic urea }(\mathrm{mg} / \mathrm{dL})\end{array}$ & $11,1^{\mathrm{a}}$ & $23,0^{b}$ & $15,1^{\mathrm{c}}$ & $22,9^{b}$ & 0,0001 & 0,051 & 0,049 \\
\hline $\begin{array}{l}\text { Uréia urinária } \\
\text { Urinary urea }(g / \text { day })\end{array}$ & $42,0^{\mathrm{a}}$ & $86,2^{\mathrm{b}}$ & $65,3^{b}$ & $122,4^{\mathrm{c}}$ & 0,0001 & 0,0007 & 0,402 \\
\hline
\end{tabular}

a,b,c letras diferentes, na mesma linha, indicam médias diferentes $(P<0,05)$.

$a, b, c$ different letters, in the same row, indicate different means $(P<.05)$.

Tabela 4 - Peso vivo $(\mathrm{kg})$ em diferentes idades das leitoas alimentadas com dietas contendo 12 ou $18 \%$ PB Table 4 - Live weight $(\mathrm{kg})$ at different ages of gilts fed diets with 12 or $18 \% \mathrm{CP}$

\begin{tabular}{lcccccc}
\hline $\begin{array}{l}\text { Nível protéico } \\
\text { Protein level }\end{array}$ & \multicolumn{4}{c}{$\begin{array}{c}\text { Momento de avaliação (idade em dias) } \\
\text { Moment of evaluation (days of age) }\end{array}$} & $\begin{array}{c}\text { Média } \\
\text { Mean }\end{array}$ \\
\cline { 2 - 7 } & 117 & 136 & 153 & 177 & 201 & 216 \\
\hline $12 \%$ & 75,9 & 96,0 & 99,0 & 124,2 & 149,9 & 151,9 \\
$18 \%$ & 75,4 & 94,6 & 98,8 & 123,1 & 147,4 & 154,7 \\
Média (Mean) & $75,6^{\mathrm{a}}$ & $95,3^{\mathrm{b}}$ & $98,9^{\mathrm{c}}$ & $123,6^{\mathrm{d}}$ & $148,6^{\mathrm{e}}$ & $153,3^{\mathrm{f}}$ \\
\hline
\end{tabular}

$a, b, c, d, e, f$ letras diferentes, na mesma linha, indicam médias diferentes $(P<0,005)$.

Não houve efeito significativo do nível de proteína $(P>0,05)$.

$a, b, c, d, e, f$ different letters, in the same row, indicate different means $(P<.005)$.

There was no significant effect of protein level $(P>.05)$

Rev. bras. zootec., 30(5):1481-1489, 2001 
al. (1997) constataram que o peso vivo de leitoas no período peri-puberdade não foi afetado pelo nível protéico da dieta (16 x 11\% PB).

Embora as fêmeas alimentadas com $12 \%$ PB apresentassem, já a partir dos 151 dias de idade, no mínimo $1 \mathrm{~mm}$ a mais na $\mathrm{ET}$, em relação às fêmeas alimentadas com $18 \%$ PB, estas diferenças não foram significativas $(\mathrm{P}>0,05$; Tabela 5$)$. Por outro lado, as leitoas que consumiram a dieta com $12 \%$ PB apresentaram um maior ganho de ET $(7,4 \mathrm{~mm})$ em relação às que consumiram $18 \% \mathrm{~PB}(4,5 \mathrm{~mm})$, quando foi considerado o aumento de ET dos 100 aos 207 dias de idade $(\mathrm{P}<0,02)$. Por ocasião do abate $(221$ dias de idade), foi constatada uma maior ET no ponto P3A $(\mathrm{P}<0,05)$, para as fêmeas recebendo $12 \% \mathrm{~PB}$ (Tabela 6).

Aumento na ET com dietas de menor teor protéico já foi reportado para machos e fêmeas da espécie suína (TJONG-A-HUNG et al., 1972; FERREIRA et al., 1983; CROMWELL et al., 1988; ADEOLA e YOUNG, 1989). Quando a deposição protéica é limitada pela ingestão de proteína, o excesso de energia em relação à proteína é depositado como gordura (ADEOLA e YOUNG, 1989). O maior ganho de ET com a dieta de baixa proteína, constatado no presente estudo, confirma o aumento observado por O’DOWD et al. (1997), por ocasião da cobertura e parto, em fêmeas que receberam uma dieta hipoprotéica, antes da cobertura e durante a primeira gestação.

O percentual de fêmeas cujo estro foi detectado foi semelhante para as fêmeas recebendo $12 \%(71 \%)$ e $18 \%$ PB (75\%), sendo que o intervalo médio entre a introdução do macho e a manifestação de estro destas fêmeas não diferiu significativamente (14,2 x 11,2 dias para o $\mathrm{T} 12 \%$ e $\mathrm{T} 18 \%$, respectivamente; $\mathrm{P}>0,05)$. JONES e MAXWELL (1974) também não verificaram diferenças na idade ao primeiro estro em leitoas alimentadas com diferentes níveis protéicos (8, 14 e $20 \%$ PB).

A presença de corpos albicans e de corpos lúteos nos ovários permitiu confirmar que todas as fêmeas, de ambos os tratamentos, haviam apresentado pelo menos uma ovulação até 30 dias após a introdução do macho e ciclaram pelo menos duas vezes, desde a introdução do macho até o abate. Não houve

Tabela 5 - Espessura de toucinho (ET) no ponto P2 de leitoas alimentadas com dietas contendo 12 ou $18 \%$ PB

Table 5 - Backfat thickness (BT) at P2 position of gilts fed diets with 12 or $18 \%$ CP

\begin{tabular}{lllllll}
\hline $\begin{array}{l}\text { Nível protéico } \\
\text { Protein level }\end{array}$ & \multicolumn{3}{c}{$\begin{array}{c}\text { Idade das leitoas (dias) } \\
\text { Age of gilts (days) }\end{array}$} & $\begin{array}{c}\text { Média } \\
\text { Mean }\end{array}$ \\
\cline { 2 - 6 } & 138 & 151 & 162 & 172 & 193 & 207 \\
\hline $12 \%$ & 12,1 & 12,9 & 13,4 & 15,7 & 17,8 & 18,2 \\
$18 \%$ & 11,6 & 11,4 & 11,9 & 14,1 & 15,9 & 15,9 \\
Média (Mean) & $11,9^{\mathrm{a}}$ & $12,1^{\mathrm{ab}}$ & $12,7^{\mathrm{b}}$ & $14,9^{\mathrm{c}}$ & $16,8^{\mathrm{d}}$ & $17,0^{\mathrm{d}}$ \\
\hline
\end{tabular}

$a, b, c, d$ letras diferentes, na mesma linha, indicam médias diferentes $(P<0,005)$.

Não houve efeito significativo do nível de proteína $(P>0,05)$.

$a, b, c, d$ different letters, in the same row, indicate different means $(P<.005)$.

There was no significant effect of protein level ( $P>.05)$.

Tabela 6 - Espessura de toucinho $(\mathrm{mm})$ ao abate (221 dias de idade) de leitoas alimentadas com dietas contendo 12 ou $18 \%$ PB Table 6 - Backfat thickness $(\mathrm{mm})$ at slaughter (221 days of age) of gilts fed diets with 12 or $18 \% \mathrm{CP}$

\begin{tabular}{lccccc}
\hline Nível protéico & \multicolumn{5}{c}{ Pontos de medida } \\
Protein level & \multicolumn{5}{c}{ Points of measurement } \\
\cline { 2 - 6 } & P1A & P1B & P2A & P2B & P3A \\
\hline $12 \%$ & 52,6 & 20,4 & 40,7 & 18,3 & 39,3 \\
$18 \%$ & 52,1 & 18,6 & 36,4 & 23,1 \\
Nível de significância & 0,894 & 0,260 & 0,087 & 15,5 & 33,1 \\
Level of significance & & & 0,058 & 0,047 & 0,223
\end{tabular}

P1: primeira costela (first rib); P2: última costela (last rib);

P3: última vértebra lombar (last lumbar vertebra).

A: três camadas de gordura (three layers of fat).

B: duas camadas de gordura (two layers of fat). 
Tabela 7 - Peso do útero (PU), comprimento dos cornos uterinos (CCU) e número de corpos lúteos (CL) de leitoas alimentadas com diferentes níveis de proteína

Table 7 - Uterine weight (UW), uterine horns length (UHL) and number of corpora lutea (CL) of gilts fed different protein levels

\begin{tabular}{lrcr}
\hline Nível protéico & PU $(\mathrm{g})$ & $\mathrm{CCU}(\mathrm{m})$ & $\mathrm{CL}(\mathrm{n})$ \\
Protein level & $\mathrm{UW}(\mathrm{g})$ & $\mathrm{UHL}(\mathrm{m})$ & \\
\hline $12 \%$ & 693,43 & 2,08 & 17,14 \\
$18 \%$ & 627,38 & 1,84 & 17,25 \\
Nível de significância & 0,55 & 0,21 & 0,93 \\
Level of significance & & & \\
\hline
\end{tabular}

efeito do nível protéico da dieta sobre o peso do útero, o comprimento médio dos cornos uterinos e número de corpos lúteos (Tabela 7).

Estudos mostraram que existe uma correlação entre o peso vivo e a idade da fêmea com o crescimento dos órgãos reprodutivos (DYCK e SWIERSTRA, 1983). PRUNIER et al. (1987) trabalharam com leitoas púberes, de 90 e $125 \mathrm{~kg}$ de peso vivo, e reforçaram esta observação pois constataram ovários mais pesados, um maior número de corpos lúteos e cornos uterinos mais compridos, nas fêmeas mais pesadas. $\mathrm{O}$ fato de as fêmeas terem alcançado peso corporal semelhante, independentemente dos tratamentos, no presente estudo, justifica que não tenha havido diferenças no peso do útero, comprimento dos cornos uterinos e número de corpos lúteos. No que diz respeito à taxa ovulatória, a ausência de efeito de diferentes níveis protéicos também foi constatada por JONES e MAXWELL (1974). Efeitos deletérios do nível protéico sobre a função ovariana, não observados no presente estudo, são mais freqüentes em fêmeas submetidas a severas restrições protéicas (O’DOWD et al., 1997). Uma redução na taxa de ovulação foi observada (CIA et al., 1996; CRISOL et al., 1997) em leitoas recebendo dietas com uma relação de 1,25 g de lisina/Mcal ED, abaixo dos 1,67 g de lisina/Mcal ED, da dieta $12 \% \mathrm{~PB}$, do presente estudo.

Apesar de as leitoas terem sido abatidas antes da cobertura, no presente estudo, foi confirmada a eficácia de uma ração com menor teor protéico em promover maior deposição de gordura e a ausência de efeitos indesejáveis sobre a puberdade e taxa ovulatória. Considerando as observações de que fêmeas acasaladas com maior ET apresentam maior número de leitões desmamados e maior número de leitegadas ao longo de sua vida reprodutiva (GAUGHAN et al., 1995), a utilização deste regime nutricional pode ser promissora para a performance reprodutiva de fêmeas suínas. Embora mais estudos devam ser efetuados para estabelecer qual o melhor momento para iniciar o fornecimento da ração hipoprotéica e por quanto tempo a mesma deve ser mantida, as dietas com baixo teor protéico se revelaram eficazes em aumentar a deposição de gordura corporal, tanto no presente estudo, cujo fornecimento iniciou aos 100 dias de idade, quanto no estudo de O'DOWD et al. (1997), no qual o fornecimento da ração hipoprotéica foi iniciado mais tardiamente (170 dias de idade).

\section{Conclusões}

O nível de $12 \% \mathrm{~PB}$ pode ser recomendado para a alimentação de leitoas de reposição, dos 100 aos 221 dias de idade, em função da maior deposição de gordura e da ausência de prejuízo no desenvolvimento corporal e puberdade, além da redução da excreção de nitrogênio para o meio ambiente.

\section{Referências Bibliográficas}

ASSOCIAÇÃO BRASILEIRA DE CRIADORES DE SUÍNOS - ABCS. 1973. Método Brasileiro de Classificação de Carcaças. Publicação Técnica n.2, 17p

ADEOLA, O., YOUNG, L.G. 1989. Dietary protein - induced changes in porcine muscle respiration, protein synthesis and adipose tissue metabolism. J. Anim. Sci., 67:664-673.

ASSOCIATION OF OFICIAL ANALITICAL CHEMISTS AOAC. 1975. Official methods of snalysis. 12.ed. Washington, D.C. 1094p.

BROWN, J.A., CLINE, T.R. 1974. Urea excretion in the pig: an indicator of protein quality and amino acid requirements. J. Nutr., 104:542-545.

CARR, J.R., BOORMAN, K.N., COLE, D.J.A. 1977. Nitrogen retention in the pig. Br. J. Nutr., 37:143-155.

CARTER, S. D., CROMWELL, G.L., LINDEMANN, M.D. et al. 1996. Reducing $\mathrm{N}$ and $\mathrm{P}$ excretion by dietary manipulation in growing and finishing pigs. J. Anim. Sci., 74(Suppl.1):59.

CHEN, H.Y., MILLER, P.S., LEWIS, A.J. et al. 1995. Changes in plasma urea concentration can be used to determine protein requirements of two populations of pigs with different protein accretion rates. J. Anim. Sci., 73:2631-2639.

CIA, M.C., EDWARDS, S.A., GLASGOW, V.L. et al. 1996. The effect of different dietary protein levels in the rearing phase (from $60 \mathrm{~kg}$ ) on body composition and reproductive performance of gilts. Anim. Sci., 62:659-660.

COOKE, R., LODGE, G.A., LEWIS, D. 1972. Influence of energy and protein concentration in the diet on the performance of growing pigs. 1. Response to protein intake on a highenergy diet. Anim. Prod., 14:35-46. 
CRISOL, M., EDWARDS, S.A., ENGLISH, P.R. 1997. Short and long term effects of protein nutrition on reproduction in gilts. Proc. British Soc. Anim. Sci., p.12.

CROMWELL, G.L., CLINE, T.R., CRENSHAW, T.D. et al. 1988. Effects of dietary protein on performance and carcass traits of barrows and gilts. J. Anim. Sci., 66 (Suppl.1):143.

DYCK, G.W., SWIERSTRA, E.E. 1983. Growth of reproductive tract of the gilt from birth to puberty. Can. J. Anim. Sci., 63:81-87.

FERREIRA, A.L., FIALHO, E.T., GOMES, P.C. et al. 1983. Níveis protéicos para suínos machos castrados e fêmeas em crescimento e terminação. R. Soc. Bras. Zootec., 12:143-162.

FOX, M.C., WATKINS, K.L., CRAIG, W.M. et al. 1988. Excess crude protein for nongravid gilts. J. Anim. Sci., 66:911-916

GATEL, F. 1994. Low protein, amino acid supplemented diets for pigs. Feed Mix, 2(4):32-34.

GAUGHAN, J.B., CAMERON, R.D.A, DRYDEN, G.M. et al. 1995. Effect of selection for leaness on overall reproductive performance in Large White sows. Anim. Sci., 61:561-564.

HOLMES, C.W., CARR, J.R., PEARSON, G. 1980. Some aspects of the energy and nitrogen metabolism of boars, gilts and barrows given diets containing different concentrations of protein. Anim. Prod., 31:279-289.

JONES, R.D., MAXWELL, C.V. 1974. Effect of protein level on growth, nitrogen balance and reproductive performance in gilts. J. Anim. Sci., 39:1067-1072.

JUST, A. 1982. The net energy value of crude (catabolized) protein for growth in pigs. Livest. Prod. Sci., 9:349-360.

KAY, R.M., LEE, P.A. 1995. Least cost diets to reduce nitrogen excretion by growing and finishing pigs. Anim. Sci., 60:519.

KESSLER, A.M. Efeito da proteina e lisina da dieta no metabolismo do nitrogênio de suínos em crescimento. Porto Alegre, RS:UFRGS, 1992. 188p. Tese (Doutorado em Zootecnia) Universidade Federal do Rio Grande do Sul, 1992.

KINYAMU, H.K., EWAN, R.C. 1994. Energy and protein metabolism of the chinese pig, J. Anim. Sci., 72:2068-2074.

LATOUR, D., LATOUR, K., WOLFINGER, R.D. 1994. Getting started with PROC MIXED. Cary, NC: SAS Institute Inc., Software Sales and Marketing Department. 121p.

LEE, P.A., KAY, R.M., FULLARTON, P.J. et al. 1995. Manipulating dietary crude protein to reduce nitrogen excreted by pigs. Anim. Sci., 60:519.

MONGÉ, H., SIMMINS, P.H., WEIGEL, J. 1997. Réduction du taux protéique alimentaire combinée avec différents rapports méthionine/lysine. In: JOURNÉES DE RECHERCHE PORCINE EN FRANCE, 29, 1997, Paris, p.293-298.

NOBLET, J., HENRY, Y., DUBOIS, S. 1987. Effect of protein and lysine levels in the diet on body gain composition and energy utilization in growing pigs. J. Anim. Sci., 65:717-726.

NOBLET, J., FORTUNE, H., SHI, X.S. et al. 1994. Prediction of net energy value of feeds for growing pigs. J. Anim. Sci, 72:344-354.
NATIONAL RESEARCH COUNCIL - NRC. 1998. Nutrient Requirements of swine. 10.ed., Washington: National Academy. $189 \mathrm{p}$.

O'DOWD, S., HOSTE, S., MERCER, J.T. et al. 1997. Nutritional modification of body composition and the consequences for reproductive performance and longevity in genetically lean sows. Livest. Prod. Sci., 52:155-165.

PEKAS, J.C. 1968. Versatile swine laboratory apparatus for physiologic and metabolic studies. J. Anim. Sci., 27:1303-1306.

PIMENTA, M.E.S.G., LIMA, J.A.F., FIALHO, E.T. et al. Efeito de níveis crescentes de proteína no balanço protéico e energético e teor de uréia sangüínea de dois genótipos de suínos. In: REUNIÃO ANUAL DA SOCIEDADE BRASILEIRA DE ZOOTECNIA, 35, 1998, Botucatu. Anais... Botucatu: SBZ, 1998. v.4, p.460-462.

PINHEIRO MACHADO, C. Efeito de diferentes níveis de proteína sobre o crescimento de suínos machos castrados e fêmeas em dois períodos da fase de terminação: Porto Alegre, RS:UFRGS, 1992. 208p. Dissertação (Mestrado em Zootecnia) - Universidade Federal do Rio Grande do Sul, 1992.

PRUNIER, A., BONNEAU, M., ETIENNE, M. 1987. Effects of age and live weight on the sexual development of gilts and boars fed two planes of nutrition. Reprod. Nutr. Dev., 27:689-700.

REESE, D.E., PEO, E.R., LEWIS, A.J. 1984. Relationship of lactation energy intake and occurrence of postweaning estrus to body and backfat composition in sows. J. Anim. Sci., 58:1236-1244.

SAS Institute Inc., 1989. SAS/STAT User's Guide, Version 6, 4.ed., v.2, Cary, NC: SAS Institute Inc., 846p.

SCHNEIDER, B.H., FLATT, W.P. 1975. The evaluation offeeds through digestibility experiments. Athens: University of Georgia Press. 423p.

TJONG-A-HUNG, A.R., HANSON, L.E., RUST, J.W. et al. 1972. Effects of protein level sequence and sex on rate and efficiency of gain of growing swine, and on carcass characteristics, including composition of lean tissue. J. Anim. Sci., 35:760-766.

TYLER, R.W., LUCE, W.G., JOHNSON, R.K. et al. 1983. The effects of level of crude protein on performance of growing boars. J. Anim. Sci., 57:364-372.

Recebido em: 19/09/00

Aceito em: 15/05/01 